\title{
P blood group phenotype, proteus antibody titres, and rheumatoid arthritis
}

\author{
C M Deighton, J Gray, D F Roberts, A J Bint, D J Walker
}

\begin{abstract}
The interrelationships between P blood group phenotype, proteus antibodies and rheumatoid arthritis (RA) were investigated in 140 patients with RA and 114 of their siblings who did not have $R A$. In the group with $R A P_{2}$ subjects had significantly higher titres of proteus antibodies than $P_{1}$ patients. This was not observed in the group without RA, or for antibodies to Escherichia coli. Although C reactive protein was the best predictor of proteus antibodies in the group with RA, the $P$ blood group had an independent and significant influence. These observations suggest a testable model in which asymptomatic carriage of proteus in the urinary tract may lead to antibody production, which in turn may be important in the pathogenesis of RA.
\end{abstract}

(Ann Rheum Dis 1992; 51: 1242-1244)

The $\mathbf{P}$ blood group system contains three known antigens: $P_{1}, P$, and $P_{k}$. The specificity is conferred by the oligosaccharide sequences in the glycosphingolipids. ${ }^{1}$ The globoside series has the structures characteristic of the $P_{2}$ phenotype, whereas the paragloboside series carries the $P_{1}$ specificity. Of these sequences at least one $\left(P_{1}\right)$ is encoded on chromosome $22,{ }^{2}$ and it seems that at least one other locus plays a part. ${ }^{3}$ The various blood phenotypes result from different combinations of these structures. Subjects with $P_{1}$, which comprise $75 \%$ of the population in Britain, express all three antigens, whereas $P_{2}$ subjects do not express $P_{1}$ but express $P$ and $P_{k}$ antigens. ${ }^{4}$

$P$ blood group antigens are expressed on cells throughout the urinary tract, where they can act as receptors for bacterial $P$ fimbriae. The ability of enterobacteria such as Proteus mirabilis and Escherichia coli to express $\mathbf{P}$ fimbriae (and thus adhere to urothelial and renal tissue) is important in the pathogenesis of urinary tract infections. ${ }^{5}$ Cross reactivity has been suggested between the $P_{1}$ blood group antigen and bacterial $P$ fimbriae, ${ }^{6}$ therefore subjects without the $P_{1}$ antigen may be able to produce antibodies against bacterial $P_{1}$ binding glycolipids, thus avoiding urinary tract infections, but may be at risk of asymptomatic bacteriuria.?

We are one of three independent groups who have shown increased proteus antibodies during the active phases of rheumatoid arthritis (RA) ${ }^{8-10}$ Ebringer et al have suggested that RA is a reactive arthritis, triggered by recurrent proteus urinary tract infections or asymptomatic bacteriuria, with proteus antibodies being cross reactive with cells expressing HLA-DR4. ${ }^{10}$ They also observed an increased isolation of proteus in the urine of patients with RA compared with controls, ${ }^{11}$ though in a preliminary study we could not confirm this. ${ }^{12}$ We have investigated $\mathrm{P}$ blood group phenotype and proteus antibodies in patients with RA to determine whether there is an association to support the hypothesis of Ebringer et al ${ }^{10}$ of asymptomatic urinary tract carriage of proteus in patients with RA.

\section{Patients and methods}

One hundred and forty patients with classica and definite $\mathrm{RA}^{13}$ and 114 of their siblings without RA were tested for proteus antibodies and antibodies to $E$ coli by indirect immunofluorescence. The details of this method have been described previously. ${ }^{8}$ Briefly, National Collection of Type Cultures (NCTC, London) strains of $P$ mirabilis (NCTC 11938) and $E$ coli (NCTC 9001) were fixed onto eight well glass slides and reacted with serial two fold dilutions of serum samples from patients starting at $1 / 10$, followed by fluorescein labelled sheep antihuman immunoglobulin (Wellcome Diagnostics, Dartford, United Kingdom). Positive and negative controls were included in each run and all serum samples were tested in duplicate and under code. On the same serum sample a $C$ reactive protein was assayed by enzyme linked immunosorbent assay (ELISA) (Emit, Syva).

For each patient with RA the following information was recorded: age, sex, disease duration, duration of morning stiffness, and disease severity using the SS index, grading pairs of joints as $0=$ normal, $1=$ tender, $2=$ swollen, $3=$ tender and swollen, and $4=$ deformed or operated upon, and summating the scores as described previously. ${ }^{14} \mathrm{P}$ Blood group status was tested in the department of human genetics using the standard tube technique, controlled with known $P$ strong, $P$ weak, and $P$ negative cells. Testing was carried out at room temperature using a low ionic strength saline solution. Commercial antisera supplied by Immunodiagnostics were used, and each specimen was tested with two different $P_{1}$ antisera whenever possible. Statistical analyses were performed using the Mann-Whitney U test, $\chi^{2}$, or multiple regression where appropriate, on the Statistical Package for the Social Sciences $\mathrm{x}$ (SPSS $\mathrm{x}$ ). 


\section{Results}

The table gives the demographic and disease characteristics of the subjects with and without RA according to their P blood group status. There was no significant difference in the demographic characteristics of $P_{1}$ and $P_{2}$ subjects within the groups with and without RA. Although the prevalence of $P_{2}$ was higher in the patients with RA (31\%) than in the other subjects $(22 \%)$, this was not significant on a $\chi^{2}$ test. Within the group with RA there was no significant difference for disease duration $(\mathrm{p}=0.9$, Mann-Whitney U test), morning stiffness $(p=0 \cdot 3)$, or $C$ reactive protein $(p=0 \cdot 1)$. The higher SS index score in the $\mathrm{P}_{2}$ patients with $R A$ did not reach conventional significance levels $(p=0 \cdot 07)$.

The figure shows the distribution of proteus antibodies in the group with $\mathrm{RA}$ for $\mathrm{P}_{1}$ and $\mathrm{P}_{2}$ subjects. Although there was considerable overlap between the groups, the titres in the $\mathrm{P}_{2}$ patients with RA were significantly higher than in the $P_{1}$ subjects $(p=0.04)$. There was no significant difference for the $P$ blood groups in the group with RA for $E$ coli antibodies, or in the group without RA for either antibody. Although the concentration of $\mathrm{C}$ reactive

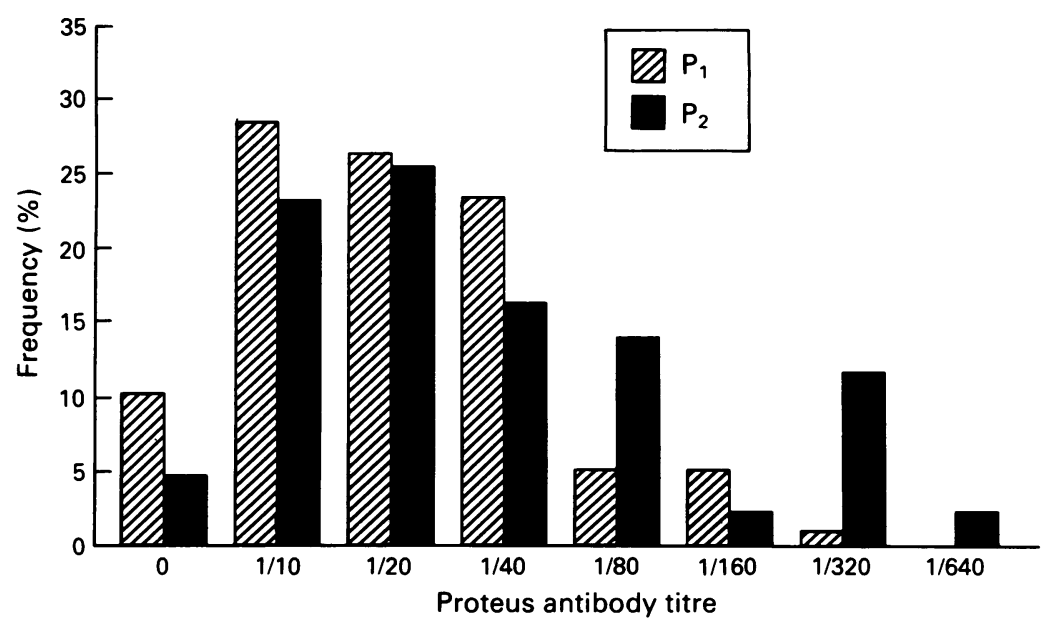

Percentage frequency distribution of proteus antibody titres in patients with rheumatoid arthritis of $P_{1}$ and $P_{2}$ blood groups. protein was not significantly different between the two blood groups, the possibility that the higher median values in the $P_{2}$ group might be the principal reason for higher proteus antibodies had to be considered. A multiple regression analysis was performed with proteus antibodies as the dependent variable (converted to an ordinal scale: no fluorescence at $1 / 10=0$, fluorescence at $1 / 10=1,1 / 20=2$, to $1 / 640=7$ ). Care was taken to check residuals for departures from the assumptions of a linear regression model. No justification was found for invalidating its use. The following independent variables were entered in a stepwise fashion into the equation: sex, age, disease duration, morning stiffness, $\mathrm{C}$ reactive protein, $\mathrm{SS}$ index, and $P$ blood group $\left(P_{1}=0, P_{2}=1\right)$. $C$ reactive protein emerged at the first step, accounting for $17.0 \%$ of the variance $(F=27 \cdot 6, p<0.001)$, with the $\mathrm{P}$ blood group at the second step, accounting for $3.6 \%$ of the variance $(F=5.5, p=0.02)$. No other variables reached significance.

\section{Discussion}

There is currently no explanation for the observation of increased proteus antibodies in subjects with active RA. Although one group could not confirm this observation, ${ }^{15}$ among the three groups who have, it appears to be relatively specific to proteus antibodies, ${ }^{10}$ relatively specific to $\mathrm{RA},{ }^{9}$ and changes in the antibody correlate highly with changes in concentrations of $\mathrm{C}$ reactive protein over time. ${ }^{8}$ Whether proteus antibodies are pathogenic or an epiphenomenon remains open to speculation. The possibility exists that the antibodies reflect a persistence of viable proteus organisms. Investigations of the possibility that patients with RA are more prone to proteus urinary tract infections have so far been contradictory, ${ }^{11}{ }^{12}$ but this does not exclude a role for proteus in a sanctuary site, such as high up in the urinary tract, or within struvite calculi.

Subjects with $\mathrm{P}_{2}$ can make antibodies to the $P_{1}$ antigens. ${ }^{1}$ It seems unlikely that the proteus antibodies are cross reactive with such antibodies, as this would have led to increased levels in $P_{2}$

Demographic and disease characteristics of the subjects studied

\begin{tabular}{|c|c|c|c|c|}
\hline & \multicolumn{4}{|l|}{ Patient group } \\
\hline & \multicolumn{2}{|l|}{$R A$} & \multicolumn{2}{|l|}{ Non-RA } \\
\hline & $P_{1}(n=97)$ & $P_{2}(n=43)$ & $P_{1}(n=89)$ & $P_{2}(n=25)$ \\
\hline $\begin{array}{l}\text { Demographic details } \\
\text { Percentage of total no of subjects } \\
\text { Percentage of women } \\
\text { Median (range) age (years) }\end{array}$ & $\begin{array}{l}69 \\
75 \\
59 \\
(25-81)\end{array}$ & $\begin{array}{l}31 \\
86 \\
56 \\
(30-76)\end{array}$ & $\begin{array}{l}78 \\
70 \\
55 \\
(18-78)\end{array}$ & $\begin{array}{l}22 \\
68 \\
54 \\
(34-68)\end{array}$ \\
\hline $\begin{array}{l}\text { RA disease details } \\
\text { Median (range) disease duration (years) } \\
\text { Median (range) morning stiffness duration (min) } \\
\text { Median (range) C reactive protein (mg/l) } \\
\text { Median (range) SS index score }\end{array}$ & $\begin{array}{l}11 \\
(1-49) \\
60 \\
(0 \text { to }>360) \\
12 \cdot 0 \\
(0-130) \\
15 \\
(4-32)\end{array}$ & $\begin{array}{l}10 \\
(1-56) \\
45 \\
(0 \text { to }>360) \\
25 \cdot 0 \\
(0-129) \\
19 \\
(6-38)\end{array}$ & & \\
\hline $\begin{array}{l}\text { Antibodies to bacteria } \\
\text { Median (range) proteus antibodies } \\
\text { Median (range) Escherichia coli antibodies }\end{array}$ & 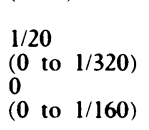 & $\begin{array}{l}1 / 20 \\
(0 \text { to } 1 / 640) \\
0 \\
(0 \text { to } 1 / 20)\end{array}$ & $\begin{array}{l}1 / 10 \\
\left(\begin{array}{lll}0 & \text { to } & 1 / 160) \\
0 & & \\
(0 & \text { to } & 1 / 40\end{array}\right)\end{array}$ & 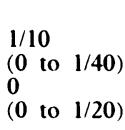 \\
\hline
\end{tabular}

${ }^{+} \mathrm{RA}=$ rheumatoid arthritis. 
subjects without $R A$ compared with $P_{1}$ subjects without RA. Previous studies have suggested that $P_{2}$ subjects are more prone to asymptomatic bacteriuria. ${ }^{7}$ This may be because they are free to produce adhesion molecule antibodies to bacteria which do not cross react with antigens expressed on their own urothelium. ${ }^{7}$ The increased titres of proteus antibodies observed in the $P_{2}$ compared with the $P_{1}$ patients with $R A$ raises the possibility that the antibodies we are detecting are directed against proteus adhesion molecules, and if confirmed would support the possibility of asymptomatic harbouring of proteus antigen or organisms in the urinary tract. Persistent asymptomatic bacteriuria could lead to a prolonged increase in proteus antibodies, which may be associated with persistent RA disease activity, ${ }^{810}$ leading to more severe disease. Although the $\mathrm{P}_{2}$ subjects had more severe disease on a clinical scale, this did not reach significance.

The multiple regression analysis suggested that $\mathrm{C}$ reactive protein was the most important predictor of proteus antibodies, though the $\mathbf{P}$ blood group exerted a smaller but independent effect. This only just reached statistical significance. There are many variables other than adhesion molecules which determine the predisposition to urinary tract infections and asymptomatic bacteriuria, however, such as urodynamics and urinary $\mathrm{pH}$, which could account for the small difference between the groups. The interpretation of these observations is open to speculation, but they suggest a testable model in which asymptomatic carriage of proteus in the urinary tract may lead to antibody production, which in turn may be important in RA. The potential interrelationships between the presence, activity, and severity of RA, P blood group, and carriage of proteus antigens or organism in the urinary tract is worthy of further research, such as the search for proteus antigens and antibodies in the urine of patients with active RA, and elucidation of the antigen(s) on proteus to which the antibodies are directed.

1 Marcus A, Janis R. Localisation of glycosphingolipids in human tissues by immunofluorescence. $\mathcal{F}$ Immunol 1970 104: 1530-9.

2 Julier C, Lathrop G M, Reghis A, et al. A linkage map of chromosome 22 , and some applications to gene mapping. Am f Hum Genet 1988; 42: 297-308.

3 Naiki M, Marcus D M. An immunochemical study of the human blood group $P_{1}, P$ and $P(k)$ antigens. Biochemistry 1975; 14: 4837-41.

4 Fletcher K, Bremer E, Schwartling G. P blood group regulation of glycosphingolipid levels in human erythrocytes. f Biol Chem 1979; 254: 11196-8.

5 Svanborg Eden C, Leffler $\mathbf{H}$. Glycosphingolipids of human urinary tract epithelial cells as possible receptors for adhering Escherichia coli bacteria. Scand F Infect Dis 1980 24 (suppl): 144-7.

6 Roland F. P, blood group and urinary tract infection. Lance 1981; i: 946.

7 Lomberg H, Eden C S. Influence of P blood group phenotype on susceptibility to urinary tract infection. FEMS Microbio Immunol 1989; 47: 363-70.

8 Deighton C M, Gray J, Bint A, Walker D J. Anti-proteus antibodies in rheumatoid arthritis same-sexed sibships. $\mathrm{Br}$ f R heumatol 1992; 31: 241-5.

9 Rogers P, Hassan J, Bresnihan B, Feighery C, Whelan A. Antibodies to proteus in rheumatoid arthritis. $\mathrm{Br} \mathscr{J}$ Rheumatol 27 (suppl 2): $90-4$.

10 Ebringer A, Khalafpour S, Wilson C. Rheumatoid arthritis and proteus: a possible aetiological association. Rheumatol and proteus: a possib

11 Wilson C, Corbett $M$, Ebringer A. Increased isolation of Proteus mirabilis species from rheumatoid arthritis patients compared to osteoarthritis patients and healthy controls. $B$ f R heumatol 1990; 29 (suppl II): 99.

12 McDonagh J, Gray J, Deighton C M, Sykes H, Walker D J Failure to isolate Proteus in the urine of rheumatoid arthritis patients more frequently than controls. $\mathrm{Br} \mathcal{J}$ Rheumatol 1991; 30 (suppl 2): 99.

13 Ropes M W, Bennett G A, Cobb S, Jacox R, Jessar R A. Revision of diagnostic criteria for rheumatoid arthritis. Bull Rheum Dis 1958; 9: 175-6.

14 Walker D J, Griffiths M, Dewar P, et al. Association of MHC antigens with susceptibility to and severity of rheumatoid antigens with susceptibility to and severity of rheumatoid arthritis

15 Murphy E A, Mowat L, Sturrock R D. Antibodies to Proteus in rheumatoid arthritis [letter]. Br $\mathcal{F}$ Rheumatol 1991; 30 390. 